\title{
VIOLETA PARRA: EL JUEGO Y EL DOLOR
}

\author{
Leonidas Morales \\ Universidad de Chile \\ Santiago de Chile, Chile
}

\section{RESUMEN / ABSTRACT}

El presente artículo tiene como objeto de estudio la lógica particular a la que parece responder la producción de la obra de Violeta Parra. Mediante el análisis preferente de una de sus modalidades, el de las arpilleras, el discurso crítico se propone demostrar, o hacer evidente, que en esa lógica de la producción artística de Violeta Parra opera, como modelo activo, la lógica del juego, concretamente del juego en los niños. Al mismo tiempo el análisis explora la naturaleza del dolor presente en la obra de Violeta y el lugar que ocupa en la lógica de la producción.

Palabras Clave: arpilleras, juego, dolor, lógica de producción, complicidad.

Violeta Parra: the game and the pain

As main object of study, this article explores the particular logic underneath the production of Violeta Parra's work. Through the analysis of one of its modes, the burlap, the critical discourse intends to demonstrate, or turn evident, that in this logic of artistic production operates, as an active model, the logic of play, specifically children's play. At the same time, the analysis also focuses on the nature of pain that circulates in Parra's work and its place in the logic of production.

KEYWORDS: burlap, play, pain, logics of production, complicity.

Recepción: 15/06/2019

Aprobación: 20/09/2019 


\section{UN ESPACIO CRÍTICO DISPONIBLE}

El 2017 se cumplieron 100 años del nacimiento de Violeta Parra y 50 de su muerte: buena oportunidad para repensar su obra y su vida. En Chile y otros países se multiplicaron los homenajes, institucionales muchos de ellos. Paralelamente, el mismo año, o apenas desfasados, se publicaron numerosos estudios críticos, unos individuales (como libro, artículos en revista) y otros integrando determinadas compilaciones. Homenajes y estudios que insistían, a su manera, en lo que cada vez resulta más indesmentible: la vigencia ostensible, a estas alturas posmodernas, de la obra de Violeta Parra, tan rica en las formas estéticas de su producción de sentido como diversa en los materiales con los que construyó cada una de las modalidades artísticas que constituyen el universo de su obra: poesía, canto, pintura, arpilleras, esculturas.

De la recepción crítica surgida dentro del contexto histórico señalado, quiero destacar dos publicaciones. Tienen en común su condición de obras colectivas. Es decir, reúnen artículos y ensayos elegidos según determinados criterios de edición. La primera, editada en inglés en 2017 por Lorna Dillon, es Violeta Parra. Life and Work. La selección de textos, algunos publicados originalmente en español y traducidos al inglés por primera vez, responde al proyecto de Lorna Dillon: ofrecer con ellos una lectura desde la práctica de la teoría y la crítica en diversos medios académicos (de Inglaterra, Estados Unidos, Chile), incluyendo algunos textos críticos que, para la editora, y desde una perspectiva histórica, son de alguna manera inaugurales.

La segunda publicación colectiva a la que me refería es un número especial de la revista francesa Artelogie, de 2019, dedicada a Violeta Parra y cuyos textos se originaron en un coloquio internacional de homenaje realizado en Santiago de Chile, en 2017, y organizado por el Consejo Nacional de la Cultura y las Artes (CNCA). Quienes participan en esta publicación son, en general, investigadores de trayectoria crítica relativamente más recientes, pero autores asimismo de discursos críticos que abren el análisis de la obra de Violeta Parra, sin olvidar sus raíces folclóricas, a las condiciones de la sociedad y la cultura modernas en su etapa de globalización.

La misma índole de la obra de Violeta Parra, o sea, la multiplicidad de los códigos que entran en su composición (verbales, pictóricos, musicales, textiles, etc.), propicia lo que fácilmente se advierte en las dos compilaciones: la proliferación en ellas de enfoques interdisciplinarios. Pero hay algo más, importante para mi ensayo: creo que, a mi modo de ver, estas dos compilaciones despliegan las problemáticas fundamentales debatidas en 
los estudios críticos en torno a Violeta Parra. La importancia para mí de un despliegue crítico de tales características, consiste en que me permite (dentro de una estrategia metodológica no exenta de riesgos, sin embargo) convertirlo en representativo y determinar el lugar que ahí ocupa el tema que en este momento me interesa. Descubro que no ocupa ningún lugar en el debate, y puesto que a mí me parece relevante en el proceso de interrogación por la construcción y el sentido en la obra de Violeta, su ausencia me anima a plantearlo y a explorar sus posibilidades de desarrollo.

De qué se trata. Para fijar el tema necesito volver a ciertos tramos de la trayectoria biográfica y artística de Violeta para subrayar en ella algunos tránsitos, directamente asociados a nuestro tema. Repetiré aquí información muy conocida, pero ineludible en la medida en que aporta algunos elementos que, a la manera de pulsiones originarias, orientarán la dirección y las formas de su arte. Ya sabemos: Violeta nació en San Carlos, sur de Chile, hija de un profesor primario, músico, y de una madre de extracción campesina, portadora de una cultura tradicional y de transmisión oral que la condicionó. Vivió la experiencia de la pobreza y de la lucha por la subsistencia. En 1935 llega a Santiago y entra a la Escuela Normal (formadora de profesores básicos), pero pronto se retira para dedicarse, junto a su hermana Hilda, a lo que verdaderamente le importaba: la música y el canto. Forman un dúo y cantan en bares canciones de un repertorio urbano y popular.

\section{FOLCLOR Y SALVACIÓN}

La década del 50 trae cambios profundos para Violeta, que redefinirán radical y definitivamente su destino artístico y biográfico. Según un testimonio de Nicanor Parra, su hermano antipoeta, él habría sido insistente en que abandonara esa música urbana y popular estereotipada en la que estaba, y se dedicara a rescatar la auténtica música del pueblo, es decir, la música campesina, folclórica (Morales, Conversaciones 134-135). Al margen de lo determinante que haya sido el consejo de su hermano, Violeta, a lo largo de la década del 50, recorrerá el país, de norte a sur, dialogando con cantores conocidos en su medio, recopilando su canto, su palabra. Es contratada por la Universidad de Concepción, en el sur, para continuar allí en la zona su trabajo de investigación. Es así como Violeta entra en contacto profundo con la música, el arte y las condiciones de vida del pueblo mapuche, componentes significativos de la obra posterior de Violeta (Véase Miranda, Loncón y 
Ramay). No hay que olvidar que las culturas tradicionales tienen elementos en común, uno de ellos su esencia comunitaria, es decir, es una cultura que se hace en y para una comunidad.

Es en el transcurso de este trabajo de recopilación, que luego será de difusión, cuando Violeta se abre a una evidencia sombría: "La tradición es casi ya un cadáver", dirá, sin omitir lo que la ha precipitado en ese estado: "Haciendo mi trabajo de búsqueda musical en Chile, he visto que el modernismo había matado la tradición de la música del pueblo" (Citado por Parra 45). Un fenómeno éste de carácter universal: en todos los espacios sociales y culturales del planeta, la modernidad (el capital) se ha demostrado incompatible con las culturas locales y tradicionales: las clausura o las somete a sus designios. Mientras subsistan como "restos", las convierte en mercancía (los turistas son los más perversos "consumidores"). Es aquí donde toma cuerpo uno de los tránsitos determinantes dentro de la evolución de la obra de Violeta. La forma de este tránsito podríamos describirla así: una vez que accede a la certeza del estado de ocaso del folclor, en lugar de renunciar a él, "asume" su destino y apuesta a su "salvación".

¿En qué sentido debemos entender estas palabras? Asumir su destino por parte de Violeta significa, primero, hacer suya la verdad ética, social, artística del folclor (la verdad cultural de un ser comunitario), pero haciéndolo sin olvidar el estado histórico de esta verdad, la inminencia de su olvido o de su fin. Y por otro lado, al decir que Violeta apuesta a su salvación, me refiero a una "salvación" que actúa en dos direcciones diferentes. Por una parte, lo salva en la medida en que lo difunde, en que lo da a conocer. No cesó nunca de comunicar el canto que ella misma había recopilado en la década del 50. La segunda forma de salvación es más compleja pero también es la que le dará a Violeta el nombre de creadora insustituible, única y original que mantiene hasta hoy y que al parecer no deja de potenciarse. Hablo de lo que podría llamarse el "proyecto" que Violeta Parra comienza a concebir. Consistiría este proyecto (difícil decir que fuera del todo consciente) en utilizar las formas y los materiales del folclor para con ellos construir un arte nuevo a través de cuya verdad la memoria de aquél (del folclor) no morirá. Un arte no destinado ya al receptor de la tradición comunitaria. Su público es urbano, porque estamos frente a un arte definitivamente moderno, portador de una verdad que solo el sujeto moderno podría descifrar. En la medida en que éste lo haga entrará en complicidad participativa con un gesto profundamente subversivo frente a las pautas sociales, culturales, artísticas de la modernidad. Esta segunda verdad supone sin duda la primera, pero al mismo tiempo la trasciende y la universaliza. 
Ahora bien, aun cuando la obra de Violeta está hecha a partir de distintos materiales y formas de la cultura tradicional, desde la palabra escrita hasta el sonido, el color, la lana o el alambre, configurando con ellos las distintas modalidades genéricas de su obra, hay una unidad que el que la oye, la ve o la lee percibe o intuye en ella. Unidad de sentido, de mundo, de ciertos procedimientos constructivos. Es frecuente encontrar en los textos críticos sobre la obra de Violeta intentos, de mayor o menor acierto, por definir esa unidad y por darle un lugar específico en el universo de la creación moderna. Por supuesto, cada uno de esos intentos tiene como fundamento crítico tales o cuales presupuestos.

\section{JUEGO Y LIBERTAD}

Me gustaría a continuación abrirle espacio a una perspectiva de análisis, como dije al comienzo, no considerada hasta ahora en los estudios críticos sobre Violeta, desde donde, creo, su obra hace visible un frente esencial de su unidad. Para dar cuenta de esta perspectiva crítica me hace falta privilegiar un determinado momento dentro del proceso creativo. No el de los productos terminados (tal o cual poema, canción, escultura o arpillera), sino el momento mismo de su producción, la identidad que lo define y que los productos delatan una y otra vez. Sin abrogar ninguna diferencia perceptible entre los productos, podemos postular, y es lo que aquí hago, la presencia operativa de una determinada lógica de la producción, de un "patrón" al que los productos remiten su forma subyacente. No pretendo en absoluto agotar esa lógica ni el sentido subyacente de sus productos, pero sí destacar uno de sus círculos sin el cual no sería concebible.

En efecto, creo que esta lógica de la producción que la obra de Violeta hace suya, la incorpora e instrumentaliza, es la lógica específica que opera en el juego. No en cualquier juego, sino en el juego propio de los niños. El juego de los niños es obviamente común a todas las culturas, tradicionales o modernas. Aun cuando en cada caso el juego (a través de los elementos que entran en él, materiales, culturales), ofrezca marcas específicas remisibles a la sociedad concreta donde se juega, mantiene sin embargo la misma lógica que lo distingue como tal. En este sentido, el arte de Violeta Parra no oculta, aunque haya permanecido sin ser destacado por la crítica, la intervención evidente en su producción de la lógica del juego. Más aún, no solo no lo oculta sino que deja a la vista el lugar de donde proviene: la cultura tradicional, o folclórica, chilena. 
Si bien es posible detectar las operaciones de la lógica del juego, en los términos dichos, en toda la obra de Violeta, bajo formas diferenciadas, trabajaré aquí, como referente inmediato, solo con una de sus modalidades genéricas: la modalidad de las arpilleras. Esta parcelación y esta elección no son desde luego arbitrarias. En mi enfoque crítico es ahí justamente, en el arte de las arpilleras, donde resultan privilegiadamente visibles los procedimientos del juego propio de los niños y de su lógica singular.

Pero, ¿qué es el juego exactamente? Las definiciones de quienes se han dedicado a estudiarlo abren horizontes conceptuales no siempre coincidentes. Para Huizinga, los juegos por "encargo" o sometidos a reglas previas, o que obran en función de un interés económico, como los juegos de azar o de competencia en los adultos, no son propiamente juegos, o lo son en otro sentido, como simulacro ${ }^{1}$. Lo que distingue al juego, según él, es un rasgo asumido también por Benjamin y que aquí hacemos nuestro. El juego, dice Huizinga, "es, antes que nada, una actividad libre. El niño y el animal juegan porque encuentran gusto en ello, y en esto consiste precisamente su libertad" (20). Benjamin subraya asimismo la importancia de la dimensión de libertad como condición del juego, cuya función es exactamente la de "liberar". Dice: "Es cierto que el juego siempre libera. Rodeados de un mundo de gigantes, los niños al jugar crean uno propio" (Escritos 83).

Que la actividad del juego, tal como la observamos en los niños, sea pues "libre", significa a la vez que conlleva una "improvisación", o también, que se declara en el momento mismo en que toma forma, en otras palabras, cuando el juego se inicia. Violeta Parra habló con insistencia de esta libertad a la que responde su obra, y sin dejar dudas al respecto. Entre las entrevistas recogidas por Marisol García en su libro Violeta Parra en sus palabras, hay algunas donde Violeta toca frontalmente este aspecto de la libertad. En una de ellas le responde a su entrevistador, Agustín Oyarzún: "Vuelvo a repetir: no soy más que una cantora y, más que eso, pintora. Todo lo que hago es porque me nace así. Escribo, pinto y canto en forma espontánea e instintiva" (91). En otra entrevista, realizada en Suiza, Hubert Joanneton, le pregunta “¿Dibuja sus arpilleras antes de realizarlas?" La respuesta: "No, no logro hacerlo. Tomo un gran trozo de tela de yute, me instalo en un rincón y comienzo a trabajar

Un juicio éste no compartido por Roger Caillois, quien sí incluye los juegos de azar y de competencia como juegos legítimos. Véase su libro Los juegos y los hombres. La máscara y el vértigo, 1986. 
en cualquier lugar de la tela que me rodea". Nueva pregunta: “¿Tiene alguna preferencia: cantar, hacer arpilleras, pintar?" Respuesta: "Depende del día. Hay días en que no hago nada con la guitarra, nada en tapiz: días en que no hago nada de nada, ni siquiera barro y no quiero ver nada" (108).

Cuando Violeta inicia alguna de sus arpilleras no lo hace pues sobre la base de una idea previa de la misma, de su forma. Ninguna imagen anterior administra su proceso exacto. El comienzo y su desarrollo son por completo aleatorios: están sometidos a las imprevistas solicitaciones del día, del ahora, de la subjetividad, del inconsciente, y desde luego de los materiales a la mano. La misma Violeta, en ocasiones distintas, ha reiterado el relato de cómo fue el inicio de su trabajo con las arpilleras. En otra entrevista del libro de Marisol García antes citado, hecha esta vez, también en Europa, por Madeleine Brumagne, confiesa: "Sentí la necesidad de bordar cuando estuve enferma, teniendo que quedarme en cama ocho meses. Y pensé que no podía quedarme en cama sin hacer nada. Un día vi lana y un pedazo de yute, y empecé a bordar cualquier cosa..." (74). En el mismo libro, en la entrevista de Joanneton, Violeta se refiere a su arpillera El Cristo en bikini, dejando a la vista la libertad con que lo teje y decide la ruta de su tejido. Dice: "lo comencé por el dedo de un pie, y luego subí y subí... Para los colores hago lo que puedo con las lanas que tengo. Para el Cristo sólo tenía lanas amarillas y azules, y con eso me las arreglé" (108).

Esta libertad así definida funda, reitero, tanto el juego de los niños como la producción, bajo formas diversas, del arte de Violeta Parra. Justamente, la perspectiva crítica que aquí me propongo introducir no es otra que la de movilizar un análisis de la obra de Violeta, en particular las arpilleras, donde la lógica del juego de los niños sea considerada como el modelo de la lógica de la producción artística de Violeta. Poner "en juego" crítico ese modelo permite acceder a una dimensión fundamental de la singularidad de la obra de Violeta, e incluso, como veremos, al modo subversivo de su inserción en la sociedad moderna.

\section{JUEGO Y MATERIALES}

No hay dudas de que ha sido Walter Benjamin el autor de algunas de las observaciones más penetrantes sobre el juego (y los juguetes) de los niños y sus propiedades. Muchas de ellas se encuentran en las páginas de su pequeño libro Escritos, formado por notas y crónicas de recepción de libros infantiles 
y exposiciones de juguetes. Me interesa por ahora uno de los temas abordados por Benjamin en las páginas de este libro.

¿Con qué juegan los niños? Los materiales con que juegan tienen propiedades particulares. Por lo pronto, son los materiales que encuentran en los lugares a donde acuden con visible predilección. Son lugares, dice Benjamin, "donde visiblemente se manejan cosas". Por ejemplo, los desechos de una edificación, de la confección de vestidos, del trabajo con muebles, etc. $\mathrm{Y}$ entonces Benjamin ofrece un comentario luminoso: "En los residuos ven el rostro que el mundo de las cosas les muestra precisamente a ellos, y sólo a ellos. No tanto porque con ellos reproduzcan las obras de los adultos, sino más bien porque con las cosas que hacen jugando entre sustancias de muy diversa índole crean una nueva y caprichosa relación. Así los niños se forman su propio mundo objetivo, pequeño entre lo grande" (Escritos 95). En otras páginas repetirá este carácter de residuo de los materiales con que el niño juega. Por nuestra parte, es oportuno recordar el testimonio de Violeta, citado antes, de cómo fue que empezó con sus arpilleras y con qué elementos.

Un breve paréntesis. ¿No hay aquí, en estos juegos, en el trabajo con residuos, una verdadera y seductora "metodología", original y productiva, que nos permitiría acceder a la construcción y al sentido, por una parte, de grandes obras de arte, donde el residuo opera como "fragmento", y por otra, de la historia y el presente de la sociedad moderna, del capital y la mercancía, donde el residuo opera como "desecho"? A propósito de este segundo caso, el mismo Benjamin, en una de sus tesis de filosofía de la historia, ponía de manifiesto un aspecto esencial del dispositivo del capital: el de no poder mantenerse ni avanzar sin la conversión en desecho de todo lo que produce, de manera de llenar así el vacío con la producción de nuevas mercancías condenadas asimismo a ser ruina y desecho ("Tesis" 46). El no hacerlo significaría la paralización del sistema y la conversión del mundo en un espacio fantasmagórico, recogido sobre sí mismo, es decir, sobre el espectáculo de su ruina.

Pero no podemos abandonar a Benjamin todavía sin antes rescatar otra de sus observaciones, continuación natural de la que destaca el carácter de residuo de los materiales del juego. En primer término, tales materiales, observa, no pueden ser sino "heterogéneos", diversos en su identidad. En la elección concreta de tales o cuales materiales para jugar, "nadie es más sobrio que el niño frente a los materiales: un trocito de madera, una piña, una piedrita llevan en sí, pese a su unidad, a la simplicidad de su sustancia, un sinnúmero de figuras diversas" (Escritos 87). 
A la luz de las observaciones de Benjamin, la obra de Violeta Parra deja ver con nitidez la naturaleza coincidente de los materiales de su propia construcción. En efecto, son también en su conjunto heterogéneos, provenientes de las prácticas cotidianas de la cultura y el arte tradicionales chilenos: alambre, yute, lana, formas estróficas, etc. Nada de sofisticación en la identidad de ninguno de ellos. Es decir, cada uno repite asimismo el rasgo de "sobriedad" advertido por Benjamin en los materiales del juego de los niños. Por último, con sus propios materiales Violeta también crea un objeto nuevo, o mejor, una figura nueva, que no solo impacta por su belleza, sino que también nos sorprende con su capacidad para penetrar e instalarse como un foco de iluminación transformadora y contestataria en la imaginación y la conciencia social de quien lo ve, lo oye o lo lee.

Los materiales del juego "juegan" a su vez con los avatares de la figura en construcción, de su transformación interna, siempre sometidos al principio de libertad que preside cada paso. En efecto, una vez elegido el material y puestas en movimiento las tentativas de construcción de una determinada figura, el proceso de ésta nunca dejará de demandar a la libertad del sujeto para que se pronuncie. Y ese pronunciamiento en cada momento puede adoptar giros imprevistos, desplazamientos, verdaderas metamorfosis de la figura. Imaginemos, por ejemplo, un niño jugando en una playa con arena húmeda. De pronto termina de levantar una pequeña columna de arena. La mira un instante y luego mira a su alrededor. Recoge un palito delgado que encuentra y con él hace dos perforaciones irregulares en la parte alta de la columna. Y basta con eso para transformarla en la cabeza de un ser humano. Luego le da un golpe a su "obra", como si no estuviera satisfecho, y todo acaba en el comienzo, en un montoncito de arena húmeda, disponible para una nueva "aventura".

En Violeta Parra asistimos a un recorrido similar de mutaciones de la figura construida. Ya la habíamos citado recordando las circunstancias en que inicia su trabajo con las arpilleras. Según su relato, todo habría ocurrido cuando se enfrentó a la realidad de que debía permanecer muchos meses en cama por una enfermedad, y ella no estaba dispuesta a estar tanto tiempo sin hacer nada. Lo que cité entonces fue lo siguiente: "Un día vi una lana y un pedazo de yute, y me puse a bordar cualquier cosa...". El texto citado continuaba en términos que aquí resultan reveladores de la transparencia con que interviene en Violeta el modelo del juego de los niños, en lo que a la libertad y las mutaciones de lo figurado se refiere. La primera vez que intentó el bordado "no salió nada", dijo esa vez. Pero agregó en seguida: "La 
segunda vez que agarré el pedazo de tela, lo deshice y quise copiar una flor, pero no pude. Al terminar el bordado no era una flor sino una botella. Quise ponerle un corcho a la botella, y éste parecía una cabeza. Le agregué ojos, nariz y boca. La flor no era una flor, la botella no era una botella, sino una mujer como aquellas que van a la iglesia para rezar todos los días. Por eso se llama La beata" (Brumagne 74).

En la misma entrevista que acabamos de citar, Violeta comenta otro episodio donde el trazado del cuerpo de la figura es intervenido, dentro de la lógica del juego, por un manejo libre de los materiales. Aun cuando el episodio en cuestión no afecta a las arpilleras sino a la pintura, vale la pena citarlo: amplía el horizonte de sujeción del trabajo artístico de Violeta a la lógica del juego. Cuenta que había estado pintando con pintura al agua, pero no soportaba sus exigencias. Dice: "Era engorroso tener que limpiar a cada rato mi pincel, es terrible trabajar así”. ¿Qué solución encontró? Una muy afín a la lógica del juego en los niños: "Entonces ahora pinto todo lo que tengo que pintar en negro de una sola vez. Con el azul sientes de una manera distinta que con el rojo. Entonces, como sé que siempre son personajes, empiezo por el negro, aquí y aquí, otro poco por acá. Y cuando ya puse todo el negro en las pinturas... me voy a limpiar mi pincel" (75).

A manera de epílogo sobre libertad y materiales. Suele ocurrir que el niño que juega se quede mirando fijamente el objeto que ha construido. Puede uno perfectamente adivinar en esa mirada un gesto como de inspección, o mejor, de "revisión" de lo hecho. No debería pues sorprendernos que de pronto el niño extienda su brazo y retire un pedazo de papel adherido o una astilla de madera sobrante. En Violeta Parra no está ausente esa mirada ni la reacción, desde luego a un nivel de conciencia que en el niño no podemos encontrar. Pero sí parece estar del todo ausente en Violeta la conciencia de que la lógica de sus procedimientos constructivos repite la lógica del juego en los niños.

Hay una carta suya de 1961 dirigida a Gilbert Favre, su pareja desde hacía un año. Un párrafo de esta carta resume muy bien lo que hemos expuesto sobre libertad, materiales e inspección final. Nombra a Gilbert con una expresión chilena popular y cariñosa. Le dice: "Sí, Chinito, yo quiero terminar mi trabajo y hacer volar por el jardín una mariposa completa. Todavía no le he quitado unas patas horribles que se me olvidó quitar, y hay una cola con pelos. Yo no soy responsable de este medio animal que parece mariposa pero al que algo le falta para ser mariposa (...). Tiene una ala inconclusa y sólo le puse una antena, y en el ala entera me olvidé de un color y de un dibujo. Ya ves que es peligroso si no termino mi trabajo. Mira las patas de la araña, cómo 
se ven de feas. Mira los pelos, mira esas tripas. No, no: es absolutamente indispensable que yo termine mi obra" (Parra 122).

\section{EL OTRO DEL JUEGO}

Un nuevo aspecto de la lógica del juego en los niños nos abre a otra dimensión de la obra de Violeta Parra, cargada esta vez de intensidad emocional, y también, en su forma extrema, de dramatismo. La dimensión en cuestión comienza a mostrar su horizonte con solo preguntamos: ¿para quién juega el niño? ¿Para él nada más? Walter Benjamin nos advierte: el niño, en su juego, "no es un Robinson" (Crusoe) (Escritos 88). En efecto, es esencial a la lógica del juego la participación en él de un otro. De los autores que han escrito páginas notables sobre el juego, Roger Caillois es quien insiste en esta condición del juego, es decir, en que no se trata de una actividad cerrada sobre sí misma (haciendo del niño una suerte de autista), sino que, por el contrario, el orden del juego supone y exige siempre de alguna manera la instancia del otro. Dentro de los comentarios de Caillois sobre el tema, cito a continuación las palabras suyas donde identifica con precisión la verdadera identidad y función del otro en el juego: "Por lo general, los juegos no alcanzan su plenitud sino en el momento en que suscitan una resonancia cómplice" (80 y 83). El otro, entonces, sería esta “resonancia cómplice". Más exactamente: el otro entra en el juego desde afuera haciéndose así cómplice del mismo.

En sus cartas y entrevistas vemos a Violeta Parra buscando incansablemente esa "resonancia cómplice" del juego de su arte en un otro. Aun cuando el otro presente identidades diversas, y diversos sean también los contextos de su figuración, en cualquier caso siempre será alguien con quien ella desea compartir su arte y convertirlo así en "cómplice" de su juego. Pero en determinados momentos, que luego revisaremos, las palabras y acciones de la propia Violeta invisten al otro de una identidad y un sentido que lleva la condición de cómplice a un plano que nos obliga a repensar desde otro ángulo el problema y el concepto mismo de autor y de obra.

Antes de examinar sus términos, y a manera de introducción, recordemos aquí el nombre de un otro más o menos previsible: el de Gilbert Favre, pareja de Violeta durante la década del 60. Un músico suizo empeñado en descubrir y promover la música autóctona americana. No quiero entrar aquí en el tema del amor en Violeta, abordado en otro lugar (Morales, Violeta 1530). Solo recordar que nunca fueron una pareja consolidada. Las frecuentes 
separaciones por trabajo de uno u otro, la frustración de Violeta frente a tales o cuales expectativas relacionadas con gestos amorosos, hacían de la pareja una relación incierta, por lo menos a la luz de las cartas de Violeta a Gilbert. En una carta le dice: "Nada tengo de ti, fuera de una promesa que palpita en el aire, sin risa ni soportes, sin amarras, sin bordes, sin contornos, sin motor que mantenga su figura deforme" (Parra 146) ${ }^{2}$. Los reclamos de amor y de presencia de Violeta son sin embargo constantes. Y de pronto surge en ella la necesidad ansiosa de encontrar en Gilbert el cómplice de su arte: "Mi pieza está llena de mis trabajos. Pongo toda mi alma en cada uno de ellos para que te gusten, para que me quieras más y más". La complicidad buscada, obviamente, es tanto artística como erótica. Incluso diría que es esta última la dominante: Violeta necesitaba siempre romper distancias con Gilbert, despejar dudas, confirmar un amor y, provisoriamente, confirmarse a sí misma como mujer amada.

Pero hay un otro, anticipé, más definitivo, del que ella aguarda, a veces con verdadera desesperación, la confirmación o la reiteración de la "resonancia cómplice": se trata del público. Desde nuestra perspectiva, este otro afecta de manera especial a nuestro análisis en la medida en que ella pone en evidencia características insospechadas de la creación artística de Violeta y de su particular relación con el otro, con el cómplice. A primera vista, podría pensarse que, al hablar de público, estuviéramos frente a una relación convencional en las prácticas cotidianas del arte. Sobre todo en las obras escénicas y musicales, el público se convierte en un referente decisivo. Hemos oído o visto mil veces a un público celebrando un concierto, junto con las palabras emocionadas del director de la orquesta o del grupo, y también otras tantas, asistir a la pobreza de público, al silencio de un fracaso, de una indiferencia, o condena explícita por parte del público.

Nada de esto constituye por cierto una novedad. Pero la forma y el sentido que adopta en Violeta, en su subjetividad, en su pensamiento, en su comportamiento, trasciende la pura función convencional del público como cómplice eventual del autor. La diferencia está en que Violeta plantea la relación entre obra, público y autor asignándoles un significado absoluto. Y esto es así porque quizás esté consciente de que su obra no es una más, de que ella pone en juego vida y muerte, la propia y la de todos, y de que solo el público puede asumir esta obra, dar fe de ella, en resumen, de salvarla 
y glorificarla haciendo propio su mundo y el modo de su construcción. En otras palabras, este público, al hacer propio el mundo de la obra, la crea, compartiendo así el lugar del autor, haciéndose su doble y su cómplice.

Por eso no sorprende su respuesta cuando Hubert Joanneton le pregunta, en su entrevista hecha en Suiza poco antes del regreso de Violeta desde Europa, por su relación con el público. Ella le dice: "No veo diferencia alguna entre el artista y el público, es el milagro del contacto. Creo estar más cerca del público que el público de mí, porque yo le canto, no canto para mí" (109). En otra entrevista, de René Largo Farías, hecha en Santiago el mismo año de su muerte, retorna el tema del público y Violeta profundiza en la relación de analogía entre público y artista: "La fusión del alma del artista con el público es lo que realmente a mi criterio, no sé si me equivoco, es lo que realmente vale en el trabajo de un artista" (113). El público en Violeta representa pues algo más que una mera "resonancia cómplice". El lenguaje de Violeta, primero, "espiritualiza" los términos al hablar del "alma" del público y del artista, y, segundo, postula entre ambos una relación programática de "fusión", pasando así del espiritualismo al misticismo. Las palabras "espiritual" y "místico", si bien pueden sugerir una acepción metafórica, apuntan de todas maneras a una relación de público-artista excepcionalmente intensa, cuyas consecuencias podremos ver más adelante.

\section{LA CARPA}

Lo que ocurrirá en la Carpa de La Reina, sobre todo su desenlace, se entenderá mejor si actualizamos antes el problema del dolor. En primer lugar no es un dolor éste reductible a tales o cuales experiencias biográficas, delimitadas por lo tanto. Es una constante, en cambio, que parece atravesar tanto su obra como su biografía, a la manera de un substrato que no dejará de encontrar "relaciones selectivas" para inundar la subjetividad y la conciencia del presente. Ya el hecho de haber asumido como suyo el destino del folclor, convertido en "cadáver" por la sociedad moderna, supone asumir a la vez el dolor de la agonía de algo amado y a cuyo olvido se niega. En una carta le dice a Gilbert: "Mis trabajos son una verdad simple y alegre dentro de la tristeza que hay en cada uno de ellos" (Parra 123). A veces el dolor parece detenerse y paralizarla. En otra carta al mismo destinatario dice: "Es que nuestra alma es tan escuálida y nuestros nervios tan tirantes, y tan feroz el martillo que golpea en la cabeza, allí en las sienes y allí entre las cejas” (Parra 139). 
En Violeta, con facilidad el dolor se socializa, es decir, hace suyo el dolor de los pobres, de los que sufren de opresión y dominación, a veces singularizados en la palabra "pueblo" con una evidente intención política y de protesta. Respondiendo una pregunta de su entrevistadora, Madeleine Brumagne, le dice: "Te voy a contar. Estaba triste porque mi abuelo era campesino. El hacía todo tipo de oficios en el campo, y el patrón le pagaba muy poco, casi nada. Había muchas personas que trabajan como él, y no ganaban mucho. Por eso hice esta tela, porque esta situación sigue sucediendo, ¿ves? Todos los campesinos en Chile viven muy pobres, como lo fue mi abuelo. No me podía quedar con los brazos cruzados. Estoy indignada con esta situación, por eso hice esta tela que se titula La revuelta de los campesinos". Un poco antes de estas palabras había dicho: "no puedo protestar. Sin embargo, a través de mis cuadros logro hacerlo" (73).

Hay múltiples referencias de Violeta al dolor convertido en su sombra y a veces en su pesadilla. En otra carta a Gilbert, el dolor, exacerbado, habla desde una soledad al borde de sus propios límites: "Te digo que estoy triste. Te digo que estoy sola. Te digo que estoy muerta. Necesito un ataúd y un discurso ridículo". En la misma carta, de pronto el dolor se transforma en una visión de muerte sepulcral: "Este cementerio que es la vida, a cada momento me muestra sus nichos y sus cruces. Y como tengo mucho miedo, te llamo para que me tomes de la mano y me ayudes a pasar por este puente peligroso" (Parra 179) ${ }^{3}$.

El dolor, dijimos, es en Violeta el substrato de su obra. Ahora bien, si la lógica de la creación en Violeta responde a la lógica del juego en los niños, entonces la formalización artística del dolor, o mejor, el modo de su "figuración" en la obra, es parte esencial de lo que deberá hacer suyo el otro, el portador de la resonancia cómplice en el juego, y mediante esta complicidad en los términos antes señalados, la obra, en su destinación, no debería chocar con un muro sino abrirse a una acogida redentora, artística y biográfica al mismo tiempo.

Violeta regresa desde Europa a mediados de 1965. Explora la situación que encuentra en Santiago a la luz de sus intereses, de cómo darle curso a sus sueños, buscando cómo establecerse. Al comienzo se integra a La Peña de los Parra, situada en la calle Carmen 340, del centro de Santiago. Un espacio de difusión musical y cultural liderado por sus hijos Ángel e Isabel. Las 
"peñas", que las hubo en Santiago y provincia, fueron lugares donde muchos cantantes (compositores a su vez) se reunían, en un ambiente relajado, para dar a conocer su canto que era el de la llamada "nueva canción", fuertemente comprometida con los movimientos revolucionarios, políticos y sociales, de esa década de los 60. La más conocida y prestigiosa fue La Peña de los Parra. Se constituyó en el modelo o paradigma de estos escenarios, con la incorporación al espectáculo de ciertas formas modernistas (Mamani 1-18). A ella concurría un público entusiasta a oír el canto de grupos y compositores como Víctor Jara, Patricio Manns, Rolando Alarcón, Ángel e Isabel Parra.

Pronto, la personalidad de tendencia autoritaria de Violeta, sus propias ideas musicales y criterios de difusión, produjeron en el grupo tensiones incómodas que al final se hicieron insostenibles. Violeta se retira. Luego se suman circunstancias que propiciarán lo que será el último gran proyecto de Violeta: el de crear un espacio propio donde el folclor fuera un eje en torno al cual giraran todas sus modalidades de construcción artística: el canto, las arpilleras, la pintura, la escultura. Pero no solo contemplaba su exhibición sino que también su enseñanza a través de talleres. Un lugar por ella imaginado como "La Universidad Nacional del Folklor".

Fernando Castillo Velasco, alcalde de una comuna entonces periférica, La Reina, se interesa en el proyecto de Violeta y le entrega en concesión un terreno en las afueras cordilleranas de la comuna, de difícil acceso. Allí Violeta levanta su Carpa, de origen circense. La construcción de la instalación responderá estrictamente a instrucciones y direcciones suyas. Ella misma distribuye los espacios, dispone el mobiliario, el formato artesanal de las construcciones de adobe donde ella vivirá. El piso, de tierra, incluyendo el de su dormitorio, cubierto de cobijas tejidas también artesanalmente.

La Carpa representaba un proyecto de espacio libre de contaminaciones de elementos estéticos de la modernidad imperante. Ariel Mamani, en un interesante artículo aborda la historia de las peñas, el paso de Violeta por una de ellas y se detiene en las diferencias entre las peñas y la Carpa de la Reina. Piensa que la Carpa de la Reina significó una vuelta a cierto "primitivismo"4. Yo diría en cambio que lo que Mamani llama primitivismo forma parte de lo que efectivamente ocurrió en esa Carpa: la instalación de un dispositivo

\footnotetext{
Aunque el término "primitivismo" no es tal vez el más apropiado, el artículo de Mamani es una excelente reconstrucción del tránsito de Violeta desde las peñas hasta la Carpa de la Reina.
} 
inédito y eminentemente subversivo desde el punto de vista de la dominante burguesía en términos estéticos, sociales, culturales.

La Carpa se inauguró en diciembre de 1965. Las expectativas de Violeta se centraban en el público, el otro cómplice del juego. Implementa toda una estrategia publicitaria para invocar y esperar la llegada del público. Entusiasmada con la buena respuesta del público que tuvo al comienzo, le cuenta a Gilbert en una carta: "Hice un brasero redondo en la tierra alrededor del palo central, bien grande. Diez teteritas y muchos fierros llenos de carne. ¿Qué maravilla es mi carpa ahora!” (Parra 190)5. Esta maravilla resultará ilusoria. La ubicación de la Carpa, a la que solo se podía llegar en taxi o en auto propio, conspiró en contra de las expectativas de Violeta: poco a poco se fue quedando sin público. La Carpa "vacía", la ausencia del otro, del cómplice, del llamado a "salvar" al artista, su obra, lo que ésta representaba, el dolor que está en su base, el suyo, el de la vida de todos, se transformó en un vacío que puso en juego la interrogación final por el sentido de su vida, de su obra. El juego de una obra (y diríamos también de una vida) sin el otro como cómplice, no puede continuar. Catherine Boyle concluye su estudio sobre "The empty space of la Carpa de La Reina" con palabras que calzan perfectamente, aunque provengan de otras premisas de análisis, con el sentido de nuestra propia conclusión: "At the end, La Carpa was a violent experience of desolation that she could no longer inhabit" $(187)^{6}$. Después de un fallido intento anterior, puso fin a su vida, en la misma Carpa, el 5 de febrero de 1967.

\section{BIBLIOGRAFÍA}

Benjamin, Walter. "Tesis de filosofía de la historia”. Ensayos escogidos. Traducción de H. A. Murena. Buenos Aires: Editorial Sur, 1967. 43-52.

Escritos. La literatura infantil, los niños y los jóvenes. Traducción de Juan J. Thomas. Buenos Aires: Ediciones Nueva Visión, 1989.

Boyle, Catherine. "Violeta Parra and de Empty Space of La Carpa de la Reina". En Dillon, Lorna (Ed.).Violeta Parra. Life and work. Tamesis: Woodbridge, 2017. 173-188.

$5 \quad$ Carta de 1966.

6 Algunas líneas temáticas que se cruzan en este "vacío" son analizadas con gran acierto en este artículo. 
Brumagne, Madeleine. "Violeta Parra, bordadora chilena". En Marisol García (ed.), Violeta Parra en sus palabras. Santiago: Catalonia, 2016. 69-76.

Caillois, Roger. Los juegos y los hombres. Traducción de Jorge Ferreiro. México DC: Fondo de Cultura Económica, 1986.

Dillon, Lorna (Ed.,).Violeta Parra. Life and Work. Tamesis: Woodbridge, 2017.

Huizinga, Johan. Homo ludens. Traducción de Eugenio Imaz. Madrid: Alianza Editorial, 2007.

Joanneton, Hubert. "Violeta Parra: Una gran artista chilena”. En Marisol García (Ed.), Violeta Parra en sus palabras. Santiago: Catalonia, 2016. 105-109.

Largo Farías, René. "Un testimonio desconocido de la Violeta Parra”. En Marisol García (Ed.), Violeta Parra en sus palabras. Santiago: Catalonia, 2016. 111-114.

Mamani, Ariel. "Para la reina... apenas una carpa. Innovación y primitivismo en La Carpa de la Reina". Artelogie13, (2019):1-18.

Miranda, Paula, Elisa Loncón, Allison Ramay. Violeta Parra en el Wallmapu. Santiago: Editorial Pehuén, 2017.

Morales, Leonidas. Violeta Parra: la última canción. Santiago: Editorial Cuarto Propio, 2003. Conversaciones con Nicanor Parra. $4^{\text {a }}$ edición. Santiago: Ediciones Universidad Diego Portales, 2014.

Oyarzún, Agustín. "Nací con una guitarra bajo el brazo". En Marisol García (Ed.), Violeta Parra en sus palabras. Santiago: Catalonia, 2016. 87-92.

Parra, Isabel. El libro mayor de Violeta Parra. $1^{\text {a }}$ edición. Madrid: Ediciones Michay, 1985. 